\title{
A DECADÊNCIA DA SOCIEDADE PATRIARCAL E SUA INFLUÊNCIA NAS ENTIDADES FAMILIARES
}

\author{
Flávia Leite do Rêgo Barros ${ }^{1}$ \\ Débora França da Silva ${ }^{2}$ \\ Francisco das Chagas Araújo ${ }^{3}$ \\ Diógenes José Gusmão Coutinho ${ }^{4}$
}

\begin{abstract}
RESUMO: O presente artigo tem como objetivo primal estabelecer a partir de pesquisas qualitativas, o entendimento doutrinário acerca da configuração da sociedade patriarcal e como este modelo ilustrava instituição familiar da época. O declínio do patriarcado trouxe mudanças que corroboraram para novas formatações pautadas na pluralidade de entes familiares, bem como, o instituto do casamento. Situar este panorama é vital para que se tenha uma perfeita visualização do arcabouço jurídico que protege estas entidades e com isso a necessidade do Direito de acompanhar a evolução da sociedade em decorrência da sua função social. No presente trabalho é desejo abordar o objeto do direito familiar, o instituto do casamento, suas origens e as devidas modificações acontecidas ao longo do século, um comparativo abrangendo o Código Civil de 1916 e o advento após a vigência do novo Código Civil de 2002, o que influenciou a sociedade, os reflexos de seus textos inovadores trazendo a ideia de um direito com sentido social que acolhe um espectro plural da família e enfatizando o valor da sócioafetividade. Com o Novo Código Civil de 2002, o conceito de família perpassa o campo do afeto, e ficam previstos os recentes agrupamentos familiares como a monoparental ou unilinear,
\end{abstract}

${ }^{1}$ Bacharel em Direito pela Universidade Salgado de Oliveira- UNIVERSO e graduada em Licenciatura Plena em História pela FAINTIVISA, especialista em História do Brasil pela FAINTIVISA, Gestão Escolar e Coordenação Pedagógica pela faculdade ALPHA, Especialização em Pesquisa Avançada pela Faculdade ALPHA e mestranda em Ciências Jurídicas pela Atenas College University - Estados Unidos. E-mail: flaviarego@bol.com.br.

2 Graduada em Direito pela UNIP- Universidade Paulista, Especialista em Direito do Trabalho, Direito Processual do Trabalho, Direito Penal, Direito Processual Penal, Direito Processual Civil pela Faculdade de Direito Damásio de Jesus, Pós-Graduada em Pesquisa Avançada pela Faculdade ALPHA e aluna regular do mestrado em Ciências Jurídicas pela Atenas College University - Estados Unidos. .E-mail: deborafrancaadv@outlook.com.

${ }^{3}$ Bacharel em Direito pela Faculdade de Olinda, especialista em Direito Público pela Escola Superior da Magistratura- Esmape, pós-graduado em Administração Pública No Centro Universitário Estácio de Sá, pós-graduado em Direito Administrativo pela Universidade Federal da Paraíba- UFPB e especialista Direito Penal e Processo Penal pela Escola Judicial do Tribunal de Justiça, Pós-graduado em Pesquisa Avançada pela Faculdade ALPHA e mestrando em Ciências Jurídicas pela Atenas College University - Estados Unidos. E-mail: chicoaraujomovel@gmail.com.

${ }^{4}$ Graduado em Biologia Pela Universidade Federal Rural de Pernambuco (UFRPE), Doutor em Biologia pela Universidade Federal de Pernambuco e Professor e Coordenador do Curso de Mestrado em Direito Pela Faculdade ALPHA - Atenas College University - Estados Unidos. Email.: alphadiogenes@gmail.com.

Revista Ibero-Americana de Humanidades, Ciências e Educação Criciúma, v.6.n.1, 2020.

ISSN - 2446-547X 


\title{
Universidade do Extremo Sul Catarinense \\ Revista Ibero-Americana de Humanidades, Ciências e \\ Educação \\ UneSC Produção e democratização do conhecimento na lbero-América
}

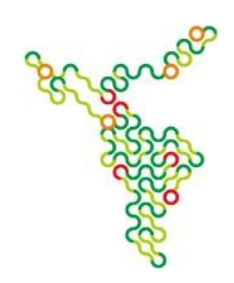

acompanhando, assim, a Carta Magna de 1988, como família a resultante do conúbio e entidade familiar oriunda da união estável, a formada pelos pais e suas progênies e dos demais agregados ligados pelos vínculos de afeto e convivência.

Palavras-chave: Afeto. Casamento. Dignidade da pessoa humana. Entidade Familiar. Família. Sociedade Patriarcal.

\section{THE DECADENCE OF SOCIETY PATRIARCHAL AND YOUR INFLUENCE THIS'S FAMILY ENTITY}

\begin{abstract}
The objective of this article is to establish from qualitative research the doctrinal understanding of human dignity and their inclusion as the main form of institution of the family, after the new changes of loved family members, as well as the Institute of marriage, to have a perfect view of the legal framework that protects these entities and with it the need of the right to monitor the development of society as a result of its social function. In this job I desire to approach the object of family law, the Institute of marriage, its origins and the necessary modifications in the Neapolitan throughout the century, a comparative covering the Civil Code of 1916 and the advent of the entry into force of the new Civil Code of 2002, which influenced society, reflections of his innovative texts bringing the idea of a social right with direction, a society. With the new Civil Code of 2002, the idea of the concept of the family, shall be as one that is constituted solely by affection, as well as new forms of family entities, such as single-parent or accompanying the unilateral, Magna Carta of 1988, recognizing the family as a result of marriage and the family entity from stable Union, formed by the parents and their descendants and relatives of other United by the ties of affection and cohabitation.
\end{abstract}

Keywords: Affection. Marriage. Dignity of the human person. Family. The family Entity. Patriarchal society.

\section{INTRODUÇÃO}

Ainda que a globalização redimensione o tempo e o espaço enquanto constituintes aceleradas e deslocadas, o passado imprime a sua marca na cotidianidade das teias sociais, e engendra o seu laivo de modo incônscio e mantem-se entranhado nas relações travadas entre os grupos nos diversos lócus comunicacionais. Os laços de parentescos continuam importantes principalmente no lide dos sujeitos pertencentes à família patriarcal- nuclear. Ainda que os demais arranjos filiais e sociais venham galgando notoriedade e acolhimento jurídico.

O passado comum traz os valores transmitidos através das gerações e o resultado cultural é o somatório das vivências partilhadas por um dado grupo, em um espaço temporal definido. Este arcabouço se mantém vivo e se manifesta nas configurações sociais. 


\section{Universidade do Extremo Sul Catarinense \\ Revista lbero-Americana de Humanidades, Ciências e \\ Educação \\ Unesc Produção e democratização do conhecimento na lbero-América}

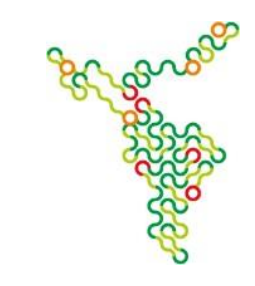

Não foge deste cenário, a família retratada aqui como uma compleição histórica, que tem a sua gênese intensamente conectada as reiteradas transformações sofridas pela humanidade pautada pelo tempo e que, por conseguinte, ilustra através da sua dinâmica de funcionamento, as concepções e preceitos que norteiam às práticas de ordem sociocultural de um dado momento histórico e temporal. Sendo assim, é plausível afirmar que a atenção às garantias do direito da família está intimamente ligada à evolução social.

Fazendo um apanhado histórico acerca da definição do instituto da família na normativa jurídica brasileira é possível perceber uma nítida mudança acerca do olhar do direito sobre o instituto familiar ao direcionálo para os sujeitos do núcleo familiar.

Hoje, as múltiplas manifestações afetivas coabitam no mesmo espaço, respondendo às demandas dos diversos nichos grupais que se entremeiam, ainda, sob a influência do ranço patriarcal manifesto com proporções distintas para cada grupo.

\section{EVOLUÇÃO HISTÓRICA DO INSTITUTO DA FAMÍLIA NO ARCABOUÇO JURÍDICO BRASILEIRO}

Ainda que a globalização redimensione o tempo e o espaço enquanto constituintes aceleradas e deslocadas, o passado imprime a sua marca na cotidianidade das teias sociais, e engendra o seu laivo de modo incônscio e mantem-se entranhado nas relações travadas entre os grupos nos diversos lócus comunicacionais. Os laços de parentescos continuam importantes principalmente no lide dos sujeitos pertencentes à família patriarcal- nuclear. Ainda que os demais arranjos filiais e sociais venham galgando notoriedade e acolhimento jurídico.

O passado comum traz os valores transmitidos através das gerações e o resultado cultural é o somatório das vivências partilhadas por um dado grupo, em um espaço temporal definido. Este arcabouço se mantém vivo e se 


\section{Universidade do Extremo Sul Catarinense \\ Revista Ibero-Americana de Humanidades, Ciências e \\ Educação \\ Unesc Produção e democratização do conhecimento na lbero-América}

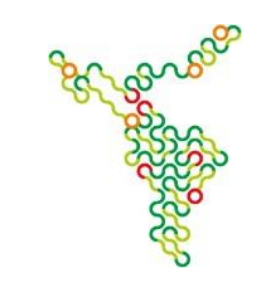

manifesta nas configurações sociais.

Não foge deste cenário, a família retratada aqui como uma compleição histórica, que tem a sua gênese intensamente conectada as reiteradas transformações sofridas pela humanidade pautada pelo tempo e que, por conseguinte, ilustra através da sua dinâmica de funcionamento, as concepções e preceitos que norteiam às práticas de ordem sociocultural de um dado momento histórico e temporal. Sendo assim, é plausível afirmar que a atenção às garantias do direito da família está intimamente ligada à evolução social.

Fazendo um apanhado histórico acerca da definição do instituto da família na normativa jurídica brasileira é possível perceber uma nítida mudança acerca do olhar do direito sobre o instituto familiar ao direcionálo para os sujeitos do núcleo familiar.

Hoje, as múltiplas manifestações afetivas coabitam no mesmo espaço, respondendo às demandas dos diversos nichos grupais que se entremeiam, ainda, sob a influência do ranço patriarcal manifesto com proporções distintas para cada grupo.

\footnotetext{
A família tinha como prerrogativa a matrimonialização, pois era voltada exclusivamente ao casamento, não admitindo outra forma de constituição familiar. Seguia os moldes patriarcais, era hierarquizada, com o homem gerindo a unidade de produção, e patrimonializada, pois seus membros correspondiam à força laboral, visando sempre o progresso da entidade familiar. (GOMES, 2012. p. 137)
}

A ideia do bem de família que tem como desígnio o abrigo do instituto da família acomodando-a sob a égide do amparo jurídico, e replicado do direito americano era o chamado homeastead, cujo escopo precípuo era de resguardar os trabalhadores no manejo das terras, outorgando escusa de confisco quanto à propriedade cultivada, com o fito de preservar e encorajar a colonização das terras pelas famílias. (RODRIGUES, 2012, p. 137). No entanto, nasceu contingente equívoco ao ensartar o bem de família no referido Código Civil. Por intermédio da reparação constitucional proposta por Feliciano Pena, 


\section{Universidade do Extremo Sul Catarinense \\ Revista lbero-Americana de Humanidades, Ciências e \\ Educação \\ Unesc Produção e democratização do conhecimento na lbero-América}

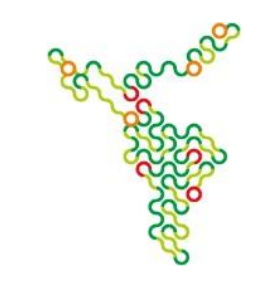

de 1912, os artigos foram disciplinados no Direito das Coisas e não como se discutia à época sob os alicerces do Direito de Família.

O aludido Código Civil tinha como escopo à proteção da família, a lei definiu a família como sendo: "enquanto viverem os cônjuges e até que os filhos completem sua maioridade, isto é, mortos os cônjuges e emancipados os filhos, perde a instituição sua razão de ser, pressupondo-se finda a necessidade de proteção" (RODRIGUES, 2012, p. 137). Neste compêndio legislativo, era vedado o divórcio e o concubinato como formatação familiar.

A definição de família perpassava pela relação de consanguinidade entre seus membros e obrigatoriamente advindos do casamento civil de natureza indissolúvel alicerçada pela Normativa Civil de 1916. (BITTAR, 2010)

O Código Civil mantinha inalterado o pátrio poder paterno e a segurança jurídica da família em prejuízo aos direitos individuais dos seus membros. $\mathrm{E}$ sobre "os filhos menores, previa o artigo 384 do Compêndio Civil de 1916 que aos pais cabia cria-los e educá-los, tê-los em sua companhia e guarda." (VELOSO, 2017, p. 27).

A nova redação do Código Civil adjudica mais poder às mulheres ao extinguir a expressão, pátrio poder, substituindo-o por poder familiar. As pessoas se encontravam sob a autoridade do mesmo chefe.

Atendendo as premissas da época, o Código civil de 1916 cumpriu a sua função social, mas diante da evolução da sociedade e novas demandas que insurgiam, exigiam da legislação brasileira posicionamentos que dirimisse tais demandas.

O panorama social na qual foi apregoada pela Constituição Federal de 1988:

Ao longo dos anos, observou-se que a família passou por expressivas modificações conceituais, bem como estruturas no transcorrer do século XX, sendo todas essas modificações absorvidas pela Constituição da República de 1988. Período este em que se promoveu o Estado Democrático de Direito no país, elegendo assim o princípio 


\section{Universidade do Extremo Sul Catarinense \\ Revista lbero-Americana de Humanidades, Ciências e \\ Educação \\ Unesc Produção e democratização do conhecimento na lbero-América}

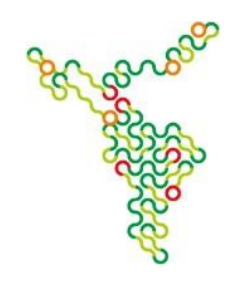

da dignidade da pessoa humana, como base, os princípios da dignidade da pessoa humana [...]. O novo texto constitucional provocou verdadeira revolução no Direito brasileiro. Com ele inaugurou um novo Direito de Família no país, como a união estável e a família monoparental, garantindo a eles a proteção do Estado. (BRANDÃO, 2010, p. 41)

$\mathrm{Na}$ atualidade, a Carta Magna de 1988 inaugurou a definição do instituto da família incorporando a vicissitude de modelo dos entes familiares em substituição ao molde da família patriarcal e vedação do tratamento desigual entre os filhos.

Essa Constituição alcançou abissal avanço no tocante a definição e proteção da família. Manteve o casamento como formato pertinente à regulamentação jurídica, "mas também não marginalizou a família natural como realidade social digna de tutela jurídica." (BRASIL, 1988)

Assim, a família que realiza a função de célula provém do casamento, como a que resulta da "união estável entre o homem e a mulher." (art. 226, §3), assim como a que se estabelece entre qualquer dos pais e seus descendentes, pouco importando a existência, ou não, de casamento entre os genitores (art. 226, §4º)." (BRASIL, 1988)

A referida normativa jurídica de 1988 inaugurou no Brasil o ideário não segregacionista à prole tida por perfilhamento dos filhos de procedência consanguínea e anuir como família à adesão derivada do companheirismo, rubricada como união estável, não obstante, reconhecer e equiparar o afeto como laço formador da família, sem diferenciar os elos parentais decorrentes do casamento ou de consanguinidade. (THEODORO JÚNIOR, 2008)

Foram aplicadas outras leis de bastante relevância, para o Direito de Família à luz das garantias fundamentais, e, em consonância com a Constituição em voga a partir da promulgação da Lei no 8.971/94 - que trata acerca do direito dos companheiros a alimentos e a sucessão - e a Lei no 9.278/96 - que gere o artigo 226, §3ํ da Constituição Cidadã, que versa sobre a união estável, afiançando sobre as relações instituídas sem a cerimonização 


\section{Universidade do Extremo Sul Catarinense \\ Revista lbero-Americana de Humanidades, Ciências e \\ Educação \\ Unesc Produção e democratização do conhecimento na lbero-América}

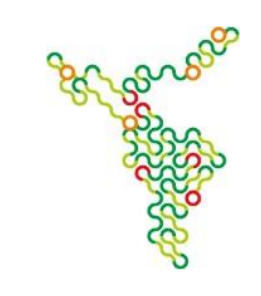

do casamento, não obstante, tem seus direitos garantidos pela escritura constitucional. Para tanto, essas normas só foram regulamentadas após a divulgação da Lei $n . .910 .406$, de 10/01/2002, inaugurando ditames do Código Civil.

Extingue-se com as novidades trazidas, em conformidade com as normativas espelhadas pela Constituição Federal de 1988 conjuntamente com a Normativa Civil de 2002, o pater poder que delibera sobre a igualdade dos cônjuges no nicho familiar. O mesmo abrange, com isso, a modernização do soluto vínculo matrimonial mediante a separação ou do divórcio. É claro que se aplicam no dispositivo legal, várias modalidades relativas à família, seja ela instituída por relações consanguíneas, pela nupcialidade à luz do preceito legal ou genuinamente a partir do afeto.

O afeto como instituto fundamental para a formação de uma nova modalidade familiar, ganha grande notoriedade entre os juristas, a jurisprudência, doutrina e os estudantes, porém a de se valer que há um grande percurso a ser cruzado. Pois, conforme foi visto é de fácil compreensão identificar o instituto familiar como "comunhão de vida, de amor, de afeto no plano da igualdade, da liberdade, da solidariedade e da responsabilidade recíproca." (DIAS, 2016, p. 05)

O modelo estratificado de família renunciou em nome da sua democratização. $\mathrm{Na}$ atualidade as relações se constroem sob a égide do igualitarismo e reciprocidade entre os parceiros. "E o traço fundamental é a lealdade, não mais existem razões morais, religiosas, políticas, físicas ou naturais que justifiquem a excessiva e indevida ingerência do Estado na vida das pessoas." (THEODORO JÚNIOR, 2008)

Há um entendimento sedimentado por renomados legisladores ${ }^{5}$ que

\footnotetext{
${ }^{5} \mathrm{Na}$ doutrina jurídica brasileira há legisladores como Sérgio Resende de Barros (2014); Luiz Edson Fachin (2010); e Rodrigo da Cunha Pereira (2015), e Álvaro Villaça Azevedo (2016) comungam do mesmo entendimento exposto por Dias (2006) sobre o instituto do afeto.
} 


\section{Universidade do Extremo Sul Catarinense \\ Revista lbero-Americana de Humanidades, Ciências e \\ Educação \\ UnesC Produção e democratização do conhecimento na lbero-América}

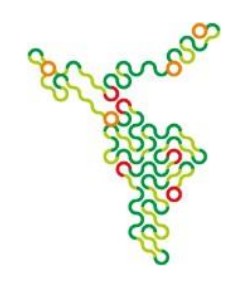

empregam o afeto como valor e lastro basilar intrínseco aos vínculos familiares, porquanto, não seja explicito a normativa constitucional, "é notável a grande aplicação nas letras de inúmeros juristas e nas decisões de outros tantos magistrados, em especial no que se trata da união entre pessoas do mesmo gênero e da parentalidade socioafetiva." (DIAS, 2009, p. 45)

A ilustre jurisperita afirma, ainda que, "é de tal ordem à relevância que se empresta ao afeto que se pode dizer agora que a filiação se define não pela verdade biológica, nem a verdade legal ou a verdade jurídica, mas pela verdade do coração." (DIAS, 2009, p. 45).

A nobre jurista defende, a nomeada adoção à brasileira, que emprega o afeto como modo de reconhece o vínculo jurídico da filiação. Logo:

Depreende-se do ordenamento jurídico pátrio, em especial da Constituição Federal de 1988, dos estudos acadêmicos e dos tribunais brasileiros que $\mathrm{o}$ afeto transcendeu a figura de elemento ou origem da família, e se tornou um valor inerente às relações familiares e deve ser encarada como um princípio que se irradia por todo o Direito de Família. (DIAS, 2009, p. 45)

Ressalta-se que "a família se desenvolve na mesma proporção que a sociedade se modifica, criando estruturas novas no intuito de se adaptar as necessidades de novas realidades no âmbito social, político e econômico." (BRANDÃO, 2010, p. 47)

Essas transformações impactaram significativamente no interior das famílias.

As alterações introduzidas visam preservar a coesão familiar e os valores culturais, conferindo À família moderna um tratamento mais consentâneo à realidade social atendendo-se às necessidades da prole e de afeição entre os cônjuges e os companheiros e aos elevados interesse da sociedade. [...]. Foi uma consequência natural das primeiras transformações trazidas pela Constituição Federal de 1988, mas, em caráter complementar e mais abrangente, buscando contemplar os direitos fundamentais, consagrando as exigências de justiça e valores éticos, objetivando a preservação da harmonia do Poder Judiciário nacional, posto que fosse capaz de modernizá-lo aos novos arranjos familiares. (DINIZ, 2008)

\subsection{O DECLÍNIO DA SOCIEDADE PATRIARCAL}




\section{Universidade do Extremo Sul Catarinense \\ Revista lbero-Americana de Humanidades, Ciências e \\ Educação \\ Unesc Produção e democratização do conhecimento na lbero-América}

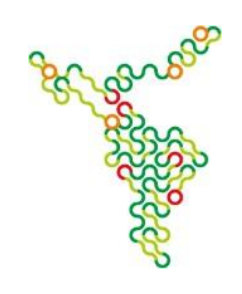

A decadência da sociedade patriarcal rege-se pelos novos princípios adquiridos pelo direito de familiar, logo, uma composição familiar agrupadora de indivíduos.

O chamado modelo patriarcal de família tem referência com o modelo senhorial e os clãs parentais, quando pensamos em modelo patriarcal, pensamos de imediato em um tipo de estrutura familiar extensa, ou seja, é um conceito de família que abriga em seu seio todos os agregados. (DINIZ, 2008, p. 69)

Existe uma definição expansiva acerca da família patriarcal como:

[...] uma família numerosa, composta não só do núcleo conjugal e de seus filhos, mas incluindo um grande número de criados, parentes, aderentes, agregados e escravos, submetidos todos ao poder absoluto do chefe de clã, que era, ao mesmo tempo, marido, pai, patriarca. O termo patriarcalismo, designa a prática desse modelo como forma de vida própria ao patriarca, seus familiares e seus agregados. (RABONI, 2018, p. 38)

Tendo como núcleo o chefe desta família, onde se define o pater poder "fazendo referência a todos os que giram em torno do núcleo centralizador dos vários tipos de relação: o patriarca. Dessa forma, o patriarca constitui-se em um núcleo econômico e um núcleo de poder." (RABONI, 2018)

Já no que concerne ao centro econômico, o chefe da família tem um numeroso séquito de "agregados, criados, escravos, etc. que dependem dele como provedor. Percebe-se que, neste modelo de sociedade, as relações econômicas contornam a figura do chefe - do pater - este, muitas vezes, era um senhor de engenho." (RABONI, 2018)

O modelo patriarcal pressupõe, segundo a historiografia, algumas premissas como:

1) A visão de uma sociedade dividida entre senhores e escravos (dominantes e dominados). Este conceito analítico seria definido principalmente por correntes historiográficas de tendências marxistas. 2) A escravidão teria desvirtuado o comportamento familiar do modelo ibérico.

3) A família brasileira seria uma adaptação ao sistema colonial, ou seja, resultado de um processo singular de criação de um determinado tipo de estrutura social.

Essa visão, proposta, sobretudo no terceiro ponto, naturalizou historicamente o modelo patriarcal. Nas discussões a respeito do tema, durante a década de vinte (quando estava em voga o processo de modernização das estruturas de produção e de comportamentos, sobretudo em Recife), cujo principal articulista foi Gilberto Freyre, no Diário de Pernambuco - jornal em que publicou diversos artigos ao 


\section{Universidade do Extremo Sul Catarinense \\ Revista Ibero-Americana de Humanidades, Ciências e \\ Educação \\ UneSC Produção e democratização do conhecimento na lbero-América}

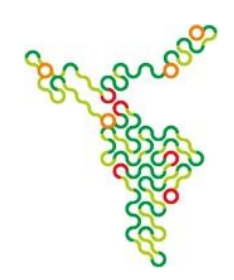

longo dessa década -, a campanha regionalista e tradicionalista encamparia esta bandeira ao pressupor que a sedução ao moderno desenraizaria as tradições familiares do ser original do Nordeste. (RABONI, 2018, p. 68)

No sopé desta discussão, é válido expor os pressupostos capitais que definem os princípios do Direito de Família, entre eles destacam-se:

O princípio da "ratio" do matrimônio e da união estável, segundo o qual o fundamento básico do casamento, da vida conjugal e do companheirismo é a afeição entre os cônjuge ou conviventes e a necessidade de que perdure por completa comunhão de vida, sendo a ruptura da união estável, separação judicial e o divórcio (MCF, art. 226, §6ㅜㅡ. CMMC, arts. 1.511 e 1.571 a 1.582) uma decorrência da extinção da afecttio, uma vez que a comunhão espiritual e material de vida entre o marido e mulher ou entre conviventes não pode ser mantida ou reconstituída. $E$, além disso, vedada está a qualquer pessoa jurídica, seja ela de direito público ou de direito privado, a interferência na comunhão de vida instituída pela família (CC, art. 1.513). (DINIZ, 2008, p. 30).

Tratar, ainda, acerca do princípio da paridade jurídica dos esposos e dos compartes, que em análise sintetizada pode-se dizer que este princípio está intimamente ligado aos seus direitos e deveres, in verbis diz:

[...] revolucionou o governo da família organizada sobre a base patriarcal. Com esse princípio desaparece o poder marital, e autocracia do chefe da família é substituída por um sistema em que as decisões devem ser tomadas em comum acordo entre conviventes ou entre marido e mulher, pois os tempos atuais requerem que a mulher e o marido tenham os mesmos direitos e deveres referentes à sociedade conjugal (CF, art. 226, §5으, e CC, arts. 1,511, in fine, 1.565 a 1.570 , $1.631,1.634,1.643,1.647,1.650,1.651$ e 1.724). (DINIZ, 2008, p. 68)

Juridicamente, as aspirações de cunho patriarcal não contemplam as demandas sociais na contemporaneidade, neste interim, "o poder do marido é substituído pela autoridade conjunta e indivisa [...] Há uma equivalência de papéis, de modo que a responsabilidade pela família passa a ser dividida igualmente entre o casal." (WALD, 2014. p. 09)

No entanto, o declínio não se traduz em esvaecimento da figura central da sociedade patriarcal que se apresenta sob uma nova aparência, agora transfigurada para o homem branco e detentor dos meios de produção "[...] com formação altamente especializada em universidades de renome, que traspassa 


\section{Universidade do Extremo Sul Catarinense \\ Revista lbero-Americana de Humanidades, Ciências e \\ Educação \\ UnesC Produção e democratização do conhecimento na lbero-América}

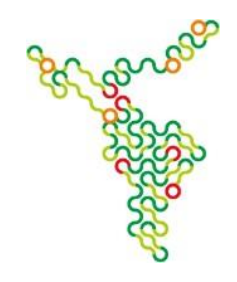

os estados como se foram tribos [...] com sucesso econômico que the garante a sua eficácia competitiva para excluir ao outro [...]." (CASTRO, 2009)

Em oposição "O não branco nem proprietário" (CASTRO, 2009, p. 13) se desfaz diante das prerrogativas socioeconômicas, logo, o tecnocrata banco e detentor de propriedades sedimenta uma figura imponente que "Em nome do Pai" se formaliza em oposição às demais constituições de personas. (DINIZ, 2008)

\subsection{A INSTITUIÇÃO DO CASAMENTO}

Inicialmente a representação da entidade do casamento era repartida entre o "confarreatio, o casamento de caráter religioso, restrito à classe patrícia, caracterizado por uma cerimônia de oferenda de pão aos deuses." (DINIZ, 2008, p. 67). Já o coemptio, reservada à plebe, celebrado mediante a venda fictícia, do pai para o marido, do poder sobre a mulher; e o uso, em que o marido adquiria a mulher pela posse, isto é, vida em comum no ínterim de um ano. (DINIZ, 2008).

Os ditames da sociedade romana que se lançavam sobre o casamento destituía o afeto enquanto estrato vital da relação e sedimentava a "estrutura de poder despótico, concentrado sob a pátria potestas do ascendente comum vive mais velho." (WALD, 2014, p. 13)

O poder do patriarca era dividido em pater famílias, o chefe da família natural, o qual exercia seu poder sobre os seus descendentes não emancipados, sua esposa e com as mulheres casadas com seus descendentes.

A igreja católica fez uma adaptação da família natural para um modelo que atendesse aos anseios cristãos, para tanto, a entidade do casamento se torna sagrada, indesatável, monogâmica e heterossexual. Originada por ato solene e constituído por descendência direta. "Este modelo prevalece até a atualidade e predomina até os dias atuais." (CASTRO, 2018, p. 52)

No interior do modelo canônico familiar, deve-se destacar a importância ao sexo, neste sentido, o ato licencioso entre o casal é requisito basilar para legitimar a união. Pois, a condição essencial está estabelecida pelo direito eclesiástico, entre o enlace e o ato procriativo, sendo este último à função 


\section{Universidade do Extremo Sul Catarinense \\ Revista lbero-Americana de Humanidades, Ciências e \\ Educação \\ Unesc Produção e democratização do conhecimento na lbero-América}

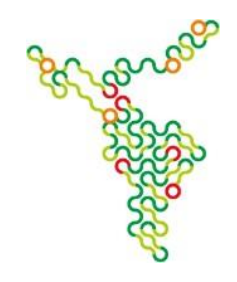

inerente para o estabelecimento da união após a consagração do casamento.

Porquanto se subtrai desta normativa que a função basilar do casamento se fundava "enquanto instituição era a procriação e, por conseguinte, a educação da prole, o que tornava justificável a prática do ato sexual dos cônjuges, autorizado no seio dessa instituição como remédio [...]" (CASTRO, 2018, p. 94). Ademais, independentemente da existência ou não de afeto entre os cônjuges, o Direito Canônico estabelecia que a união decorrente do casamento fosse "indissolúvel, isto é, não se pode dissolver por vontade dos cônjuges, exceto pela morte." (CASTRO, 2009, p. 53).

Uma das temáticas de maior interesse para o Direito Canônico debruçara-se sobre legislatura familiar, sendo que a sua tutela esteve ligada intimamente "a igreja católica que sempre se preocupou com a organização da família, disciplinando-a por sucessivas regras [...] por largo período histórico vigoraram, entre os povos cristãos, como seu exclusivo estatuto matrimonial."(GOMES, 2015, p. 41)

No sopé da contemporaneidade "a existência de um consenso sobre a diversidade de arranjos familiares, sobre o caráter temporário dos vínculos conjugais e sobre questões ligadas à reprodução humana e liberalização dos costumes." (GOMES, 2015, p. 41)

Há uma sinalização para as constantes transformações no arcabouço familiar deslocando se liame da ótica socioeconômica e transferindo-se para a nucleação com base nos ditames da afetividade entre seus membros consanguíneos ou alocados à família por vias diversas que não perpassam pela hereditariedade.

Já não é mais possível fixar um modelo familiar uniforme, uma vez que a família passa por uma mutabilidade inexorável, apresentandose sob tantos e diversos prismas quantas forem às possibilidades de se relacionar. Ela deixa de ser compreendida como núcleo econômico e reprodutivo e passa para uma compreensão socioafetiva, com novos padrões e arranjos familiares, que refletem de forma significativa em vários setores como a arte, ciência, religião, moralidade, educação, direito, política, vida familiar. (MIOTO, 2014, p. 53). 


\section{Universidade do Extremo Sul Catarinense \\ Revista lbero-Americana de Humanidades, Ciências e \\ Educação \\ UnesC Produção e democratização do conhecimento na lbero-América}

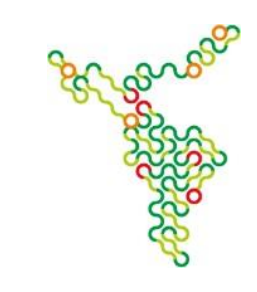

Assim, o maior instituto da união familiar, para as jurisprudências e doutrinas já existentes e pela própria legislação, é o afeto. Com isso, a união entre seres para a formação de uma instituição familiar é baseada na afetividade, não necessitando de laços de consanguinidade e muito menos da instituição do casamento para se concretizar.

\subsection{O AFETO COMO SUBSTRATO DA UNIÃO FAMILIAR}

O afeto como instituto fundamental para a formação de uma nova modalidade familiar, ganha grande notoriedade entre os juristas, a jurisprudência, doutrina e os operadores do direito, porém a de se valer que há um grande percurso a ser cruzado. Pois, conforme foi visto é de fácil compreensão identificar o instituto familiar como acordo de convivência afetiva pautada em preceitos próprios da igualdade entre os sujeitos e responsabilidade mútua no gerenciamento do matrimônio.

A partir da nova formatação familiar onde o "traço fundamental é a lealdade, não mais existem razões morais, religiosas, políticas, físicas ou naturais que justifiquem a excessiva e indevida ingerência do Estado na vida das pessoas." (MASCOTTE, 2009, p. 03)

O afeto alçou o patamar de relevância tamanha que "se pode dizer agora que a filiação se define não pela verdade biológica, nem a verdade legal ou a verdade jurídica, mas pela verdade do coração".(MASCOTTE, 2009, p. 05) Com estas palavras, a citada autora, defende a propalada adoção à brasileira, que utiliza o afeto como modo de reconhece o vínculo jurídico da filiação.

\subsection{O RELEVO DOS RELACIONAMENTOS HOMOAFETIVOS ENQUANTO INSTITUIÇÕES FAMILIARES ACOLHIDAS PELA LEGISLAÇÃO PÁTRIA}

O direito não pode ser furtar as demandas nascidas a partir das conjugações sociais, assim, nasce a inescusável discussão acerca da legitimação dos relacionamentos homoafetivos e no arcabouço jurídico 


\section{Universidade do Extremo Sul Catarinense \\ Revista lbero-Americana de Humanidades, Ciências e \\ Educação \\ UnesC Produção e democratização do conhecimento na lbero-América}

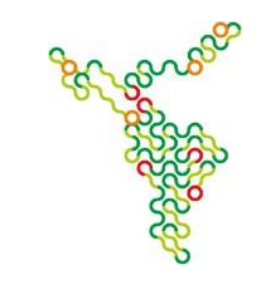

brasileiro. Aqui, se consubstancia o entendimento que "a homossexualidade não deveria ser explicada, ela apenas existe." (SPENCER, 1999, p. 35)

Os dispositivos legais nacionais tratavam os relacionamentos contínuos e duradouros entre parceiros do mesmo gênero como sociedade de fato, (SOARES, 2000), esse entendimento foi corroborado pela doutrina e jurisprudência brasileira, posteriormente houve a mudança de status em que conferiu a essas relações o reconhecimento como entidades familiares.

A urgência em disciplinar essas relações familiares, ainda que setores sociais mais conservadores militem contrariamente, o amparo jurídico torna-se "[...]indispensável por impor aos nossos julgadores, soluções e respostas diante de querelas nas relações nos diversos ramos do direito, seja o direito de família, previdenciário, sucessório." (MELO, 2005). E demais espaços de representações jurídicas que anseiam por respostas diante dessas querelas.

A Lei 11.340/06 evoca juridicamente o resguardo da mulher diante da violência doméstica, e aponta um novo norte na legislação brasileira diante do reconhecimento das entidades familiares quando diz:

A chamada Lei Maria da Penha, que cria mecanismos para coibir a violência doméstica contra a mulher, modo expresso, enlaça as relações homossexuais. Isto está dito no seu artigo 2..: "Toda mulher, independentemente de classe, raça, etnia, orientação sexual [...] goza dos direitos fundamentais inerentes à pessoa humana". O parágrafo único do artigo 5. afirma que independem de orientação sexual todas as situações que configuram violência doméstica e familiar.(DINIZ, 2008, p. 84)

Diante da gritante demanda social que resguardasse juridicamente os casais homoafetivos houve um expressivo soerguimento jurídico acerca dos direitos dos indivíduos que constroem relações homoafetivas. Na atualidade, a Corte brasileira atesta que há verossimilhança jurídica entre os direitos próprios das relações estáveis entre casais compostos por homem e uma mulher e entre as relações estabelecidas com pares do mesmo gênero. 
Universidade do Extremo Sul Catarinense Revista lbero-Americana de Humanidades, Ciências e Educação

UnesC Produção e democratização do conhecimento na lbero-América 


\section{CONSIDERAÇÕES FINAIS}

Diante do exposto, e conforme ilustrativos acima acerca de casos já aceitos pela Doutrina e Jurisprudência majoritária bem como pelas decisões dos Tribunais de Justiças estaduais. Ficou ainda mais evidente que dia após dia os núcleos de família brasileira não são mais restringidos ao homem e a mulher, sendo pai e mãe. As diversas configurações vão além da família patriarcal e mononuclear.

Hoje, as amarras jurídicas cederam lugar para a supremacia do afeto. Casamentos homoafetivos e heterossexuais subsistem pela égide da afetividade, por conseguinte, essas relações são mais fluídas e dinâmicas. E o direito não pode se refutar a essa engrenagem social na qual o casamento figura como espelho.

A Constituição Federal augura duas formas de entidades familiares: aquela formada pelos seus pais e seus filhos, e a monoparental, prevista no $\S^{\circ}{ }^{\circ}$ de seu art. 226, formada por somente um dos genitores e prole, hoje tão frequente quanto à chamada tradicional. No entanto, a dinâmica social exigiu respostas jurídicas acercas das demais configurações afetivas que existiam de fato, mas não eram alcançadas pelo direito.

A equiparação entre casamentos entre pessoas com mesmo gênero e casais com orientações sexuais diferentes sanou uma lacuna jurídica e se mostrou como um exemplo gritante acerca da necessária adequação das normas jurídicas em consonância com as querelas sociais. Assim deve proceder ao Direito.

O direito de família moderno deve adotar uma perspectiva pluralista da família que enfatiza o valor jurídico da sócio-afetividade, de onde decorreria a ideia de que nem só o parentesco e a adoção seriam os subsídios de uma entidade familiar. Os laços de afeto, relegados anteriormente a um segundo plano diante dos laços de sangue, foram alçados a um mesmo patamar. 


\section{Universidade do Extremo Sul Catarinense \\ Revista Ibero-Americana de Humanidades, Ciências e \\ Educação \\ Unesc Produção e democratização do conhecimento na llbero-Améríca}

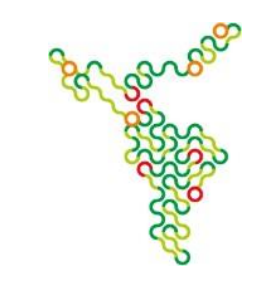

No direito de família pós-modernos prevalece à dignidade do indivíduo humana, a solidariedade, a inclusão e o afeto. $O$ desejo pelo reconhecimento de tal transformação. Logo, várias outras modalidades de entidades familiares são percebidas em nossa sociedade. A ordem da pós-modernidade é incluí-las, respeitá-las e conhecer que existem por laços de afeto, e não apenas de sangue. Sendo assim é dever do Estado e do Direito acompanhar a evolução da nossa sociedade sob todos os aspectos.

É conclusivo reconhecer que sob a batuta da afetividade as relações de conjugalidade se constroem e se mantêm fluidas e dinâmicas. E cabe ao Direito centrar seu olhar sobre o casamento que figura com espelho desta engrenagem social corporificada pelo afeto em detrimento das atas jurídicas.

No interior destas relações os filhos são epistemologicamente filhos, independe da sua origem e comungam da premissa jurídica em que o afeto deve ser a túnica capaz de garantir a convivência em que todos os sujeitos sejam atendidos em suas demandas de ordem afetiva.

\section{REFERÊNCIAS}

BITTAR, Carlos Alberto. Direito de Família. $2^{\mathrm{a}}$ ed. Rio de janeiro: Forense Universitária, 2010.

BRANDÃO, Silvia Lúcia de Souza. A união estável no Código Civil de 2002: Considerações sobre o novo paradigma de família no Brasil contemporâneo e suas implicações no ordenamento jurídico, 2010. disponível em http://www.funcesi.br/portals/1/uniao\%20estavel.doc. Acesso em 05. jun.2018.

BRASIL, Constituição (1988). Constituição da República Federativa do Brasil. Brasília, DF: Senado, 1988.

CASTRO, Rocio. A necessária reflexão sobre a cultura patriarcal na era da globalização, 2009. Disponível em: http://www.cult.ufba.br/enecut.pdf. Acesso em 17.06.2018.

CUNHA, Matheus Antônio da. O conceito de família e sua evolução histórica. Portal jurídico Investidura, Florianópolis/ SC, 27 de set. 2010. 


\section{Universidade do Extremo Sul Catarinense \\ Revista lbero-Americana de Humanidades, Ciências e \\ Educação \\ UneSC Produção e democratização do conhecimento na llbero-América}

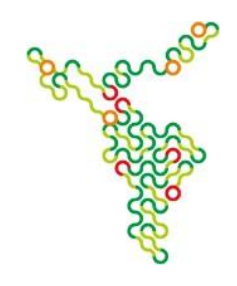

Disponível em: http://www.funcesi.br/portals/1/uniao\%20estavel.doc. Acesso em 06. jun.2018.

DIAS, Maria Berenice. Violência doméstica e as uniões homoafetivas . Jus Navigandi, Teresina, ano 10, n. 1185, 29 set. 2016.

DINIZ, Maria Helena. Curso de Direito Civil brasileiro: Direito de Família. 23. Ed. São Paulo: Saraiva, 2008.

GOMES, Orlando. Direito de Família. ed. Rio de Janeiro: Forense, 2015.

GOMES, Roseane dos Santos. Evolução do Direito de Família e a mudança de paradigma das entidades familiares. Disponível <em https://www.viajus.com.br/viajus.php?pagina=arigos\&.id+1006>. Acesso em: 20 de mai. 2018.

MASCOTTE, Larissa. As uniões estáveis homoafetivas e o Direito. Jus Navigandi, Teresina, ano 13, n. 2199, 9 jul. 2009. Disponível em: http://jus2.uol.com.br/doutrinaid=13116>. Acesso em: 11 jun. 2018.

MIOTO, Regina Célia Tamaso. Trabalho com famílias: um desafio para os Assistentes Sociais. In: Revista Textos \& Contextos. Vol. 3, No 1, 2014.

RABONI, André. A admissibilidade da Cláusula de não indenizar e da cláusula limitativa do dever de indenizar numa comparação jurídica entre os ordenamentos brasileiros e francês. Disponível: https://acervodigital. ufpr.br/bitstream/handle/ \%20-\%20D\%20-. Acesso em 12 jun. 2018.

RODRIGUES, Sílvio. Direito Civil. São Paulo: Saraiva, 2012. SOARES,

Orlando. União estável. Rio de Janeiro: Forense, 2010.

SPENCER, Colin. Homossexualidade: uma história. Trad. Rubem Mauro Machado. 5.ed. Rio de Janeiro: Record, 2009.

THEODORO JÚNIOR, H. apud GOMES. Direito de Família. 16. ed. Rio de Janeiro: Forense, 2008.

VELOSO, Zeno. Direito brasileiro da filiação e paternidade. São Paulo: Malheiros, 2017.

VENOSA, Silvio Sálvio. Direito Civil- Direito de família. São Paulo, 2015.

WALD, Arnoldo. O novo direito de família. 15 ed. São Paulo: Saraiva, 2014. 